\title{
A New Compression-Torsion-Tribometer with Scalable Contact Pressure for Characterization of Tool Wear during Plastic Deformation
}

\author{
Marco Teller, Simon Seuren, Markus Bambach, and Gerhard Hirt \\ Institute of Metal Forming (IBF), RWTH Aachen University, Intzestraße 10, 52056 Aachen, Germany \\ Correspondence should be addressed to Marco Teller; teller@ibf.rwth-aachen.de
}

Received 31 July 2014; Accepted 20 November 2014

Academic Editor: Matthias Scherge

This Conference Paper is based on a presentation given by Marco Teller at "European Symposium on Friction, Wear, and Wear Protection" held from 6 May 2014 to 8 May 2014 in Karlsruhe, Germany.

Copyright (C) 2015 Marco Teller et al. This is an open access article distributed under the Creative Commons Attribution License, which permits unrestricted use, distribution, and reproduction in any medium, provided the original work is properly cited.

\begin{abstract}
A contact pressure which reaches up to ten times the yield stress of the workpiece material is characteristic for cold extrusion processes. Common tests for friction and wear are limited to rather low contact pressures. Thus, the aim of this paper is to present a new compression-torsion-tribometer which is able to scale the contact pressure to a multiple of the yield stress of the workpiece. In order to enable a contact pressure that greatly exceeds the yield stress of the workpiece material, the workpiece specimen is encapsulated laterally. As main parameters, contact pressure, glide length, and relative velocity can be adjusted independently, thus allowing for multiple load cycles. The resulting torque is measured continuously as an indicator for wear. Afterwards wear can be also quantified by examination of surfaces. Hence, the developed setup enables a comparison of tool surfaces and coatings and a characterization of wear behaviour under high contact pressure.
\end{abstract}

\section{Introduction}

A characteristic of cold extrusion processes is the high contact pressure between workpiece and tool [1]. It can reach up to ten times the yield stress $\sigma_{y}$ of the workpiece material [2]. The high stresses highly influence the lifetime of the tools in extrusion processes. For the determination of friction and wear, different methods were investigated in the past. On the one hand there are the "classical" experimental setups for friction measurement involving partial plastic deformations, for example, the pin-on-disk test, the stripdrawing test, or the draw-bending test [3]. On the other hand, there are measurement methods for friction involving bulk plastic deformations like the Burgdorf-ring-compression test [4], the conical tube-upsetting test by Kopp and Philipp [5], or a sliding-upsetting test by Hemyari [6]. A multiple performance of these experiments allows also an estimation of tool wear.
In addition to the high contact pressure, a long glide distance is essential for tool wear characterization. A cyclic loading which is representative for high production rates and a frequent use of the tools should be also represented in the experiment. For the achievement of long glide lengths, a rotational movement of the contact partners is favourable. Moreover, a wear indicator is necessary to characterize the tribological behaviour during the testing process. Both can be fulfilled by a torsion-tribometer. The main idea of a torsiontribometer is the use of a rotating specimen and an axially loaded counterpart. The torque transferred from the rotating side to the static side is a direct indicator for friction and wear.

Already in the past torsion-tribometers were developed by other researches. Lauterbach et al. [7] analysed the friction coefficients of electrolytic copper and pure aluminium against a hardened punch under approximately $500 \mathrm{MPa}$ load. The relative movement between the two specimen parts is a quarter-revolution. 
Pal [8] tested brass against a high speed steel with an apparatus mounted on a lathe and reached in his experiments up to $360 \mathrm{MPa}$. Due to an unrestricted increase of the contact area, the normal contact pressure was just slightly above the yield stress of the tested material.

Hora et al. [9] and Becker et al. [10] used a modified torsion machine for examination of the behaviour of different coatings in contact with the aluminium alloy EN-AW6082 for a usage in hot extrusion. Therefore, tests were conducted for increased temperatures (up to $500^{\circ} \mathrm{C}$ ) and the applied loads reached up to $60 \mathrm{MPa}$. The testing machine enables different sliding velocities for the specimens with a conical-ring contact area. The influence of the parameters pressure, velocity, and temperature was examined in long-term experiments.

In this work a new compression-torsion-tribometer which is able to scale the contact pressure to a multiple of the yield stress of the workpiece is introduced. Moreover it enables the simulation of a cyclic loading of the tool. As direct indicator for changing tribological conditions in the contact area, the resulting torque is measured over the complete testing period. The new compression-torsion-tribometer will be used in future works to characterize the friction and wear behaviour of different surface treatments and coatings and examine their suitability in dry state. Therefore, the current setup is constructed for an investigation of the wear behaviour between pure aluminium (the workpiece) and steel (the tool) at room temperature and without lubrication. The main wear mechanism in cold extrusion of aluminium is the adhesion of workpiece material on the tool surface. The galling of aluminium could already influence the quality of formed parts and by that decrease the service time of the tool. Hence, in our work, we focus on aluminium adhesion on the tool specimens surface.

This paper is structured as follows. In Section 2, the experimental setup and the design of the specimens are introduced. General experimental results, the possibilities of a cyclic loading with the new compression-torsion-tribometer, and the shape of the surfaces (tool and workpiece) after testing are presented in Section 3. A conclusion and a perspective on future work are given in Section 4.

\section{Experimental Setup}

2.1. Testing Equipment. The compression-torsion-tribometer is designed as a tabletop unit. In Figure 1 it can be seen that the different parts are mounted on a base plate of steel. Basically the tribometer is separated into a rotating (left side) and an axially loaded static part (right side).

On the left-hand side the engine and gear are placed. The engine is a three-phase motor with a power of $P=1.1 \mathrm{~kW}$ and a maximal rotation speed of $n=1400 \mathrm{~min}^{-1}$. A worm gear with a gear ratio of $i=19$ is used. Hence the maximum torque $M_{\max }$ is

$$
M_{\max }=\frac{P i}{2 \pi n}=142.56 \mathrm{Nm}
$$

The rotation speed and the number of revolutions of the driveshaft are measured via an encoder-wheel mounted on

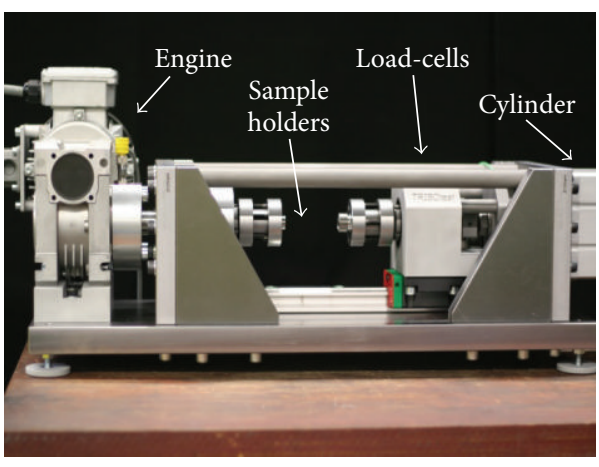

FIGURE 1: Setup of the compression-torsion-tribometer with wormgeared engine, sample holders, load-cells, and three-stage pneumatic cylinder (from left to right).

the shaft. The encoder-wheel has eight measuring points so that it is possible to measure one-eighth of a revolution of the shaft. Moreover a clamping sleeve is attached to the end of the driveshaft. The clamping sleeve is the intake for one part of the specimens.

On the right-hand side a pneumatic cylinder and the measurement equipment are located. For the compression of the workpiece specimen a three-stage pneumatic cylinder with a maximal compression force $F=18 \mathrm{kN}$ is used. The force is scalable continuously. For the filling of the compression-cylinder a valve is used. It regulates how much load will be applied.

In front of the cylinder a data logger is integrated. The logger contains two load-cells and a bearing for a second driven shaft. One of the load-cells is used for tracking the applied load from the cylinder. The second load-cell is used for the measurement of the transferred torque from the rotating part to the static part of the tribometer. Therefore, a torsion arm with the length of $30 \mathrm{~mm}$ is installed. Another intake for the second part of the specimen is placed on the second driven shaft.

The data logger and the driven shaft are fixed on a slide. Due to the filling of the pneumatic cylinder, this slide will be moved along a rail in order to bring both sides of the tribometer in contact.

The connecting rods between the two sides of the tribometer are necessary for an increase of the overall stiffness of the machine. This guarantees a constant axial alignment under operational load.

2.2. Specimen Design. The specimens for the compressiontorsion-tribometer are separated into two main parts, on the one hand the workpiece part and on the other hand the tool part (Figure 2).

The workpiece material is by definition the material with the lower yield stress. The designated contact area between the specimens is the ring surface shown in red in Figure 2. A circular contact surface guarantees that all parts of the contact area are in motion and an origin with no relative motion does not exist. 


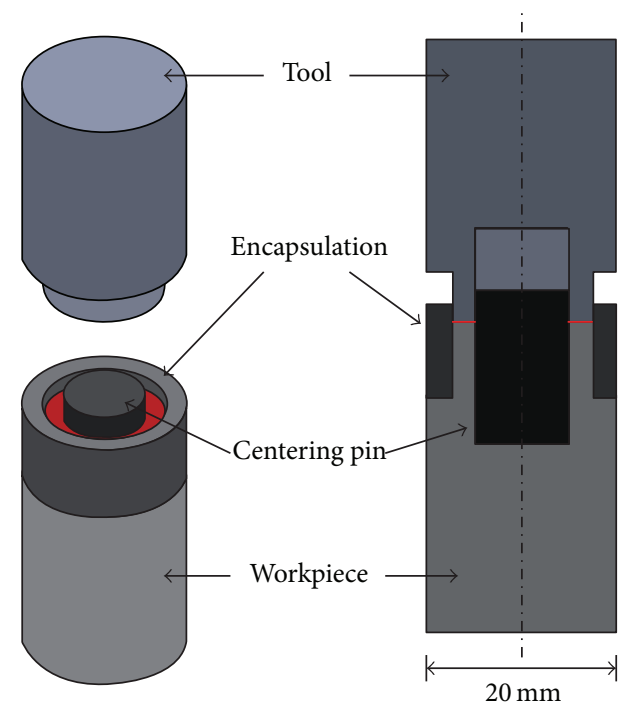

FIGURE 2: Tool specimen and workpiece specimen with encapsulation ring and centering pin for the compression-torsion-tribometer in general setup (left) and in sectional view in contact (right); designated contact area in red.

In order to enable high contact pressures that greatly exceed the yield stress of the workpiece material, the workpiece specimen is encapsulated laterally by a ring and the centering pin. Additionally both parts support the axial alignment of the two specimen parts. It can be seen that inside the tool specimen a hole for a centering pin is integrated in order to avoid additional friction surfaces.

The specimens have an outer diameter of $20 \mathrm{~mm}$ and the hole for the centering pin has a diameter of $10 \mathrm{~mm}$. Because of the thickness of the encapsulation ring $(2.5 \mathrm{~mm})$, the designated contact area has a size of $98.17 \mathrm{~mm}^{2}$. Due to the circular surface the glide path along the radial direction is increasing from 31.4 to $47.1 \mathrm{~mm}$ per revolution. For the same reason the rotation velocity is 1.5 times higher on the outer edge than on the inner edge.

The following parameters can be adjusted:

(i) rotation speed $n$ of the driveshaft,

(ii) load force $F$,

(iii) number of load cycles,

(iv) duration of load,

(v) duration of contact break.

The adjustable parameters allow for a variation of glide path, relative velocity, and contact pressure. Moreover, it is possible to simulate the multiple use of the tool part by defining a high number of load cycles.

Measured parameters within the test are as follows:

(i) contact force,

(ii) rotation velocity,

(iii) number of rotations,

(iv) time,

(v) transferred torque.

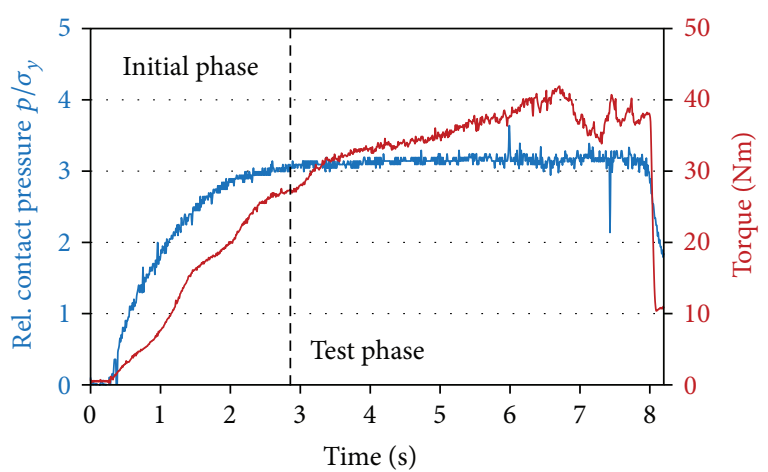

FIGURE 3: Relative contact pressure (blue) and transferred torque (red) versus testing time.

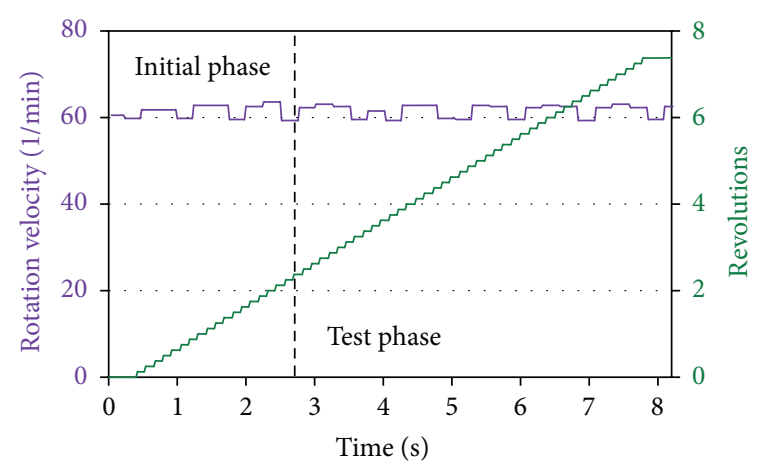

FIGURE 4: Rotation velocity (purple) and number of revolutions under pressure (green) versus testing time.

The first four measurements define the load spectrum of the test. The last measurement is a wear indicator. Together with the measured (e.g., topography, hardness, and layers on the surface) and known properties before testing (e.g., the materials of the specimens and their state) a description of the complete tribological system is feasible.

\section{Results and Discussion}

3.1. General Testing Procedure and Output. In this section the common experimental output of the new compressiontorsion-tribometer is presented. The workpiece material is annealed aluminium (AA1050-O) and as tool material the tool steel DIN 1.2343 (AISI H11) is used. The testing parameters were five revolutions at full load (three times yield stress of the aluminium) with a rotation velocity of $60 \mathrm{~min}^{-1}$. The setup was not lubricated. In Figures 3 and 4 the measured parameters (relative contact pressure, transferred torque, rotation velocity, and number of revolutions) during the experiment can be seen.

The pneumatic cylinder needs approximately three seconds (initial phase) to generate the designated full load of three times the yield stress of the workpiece material. Afterwards the pressure keeps on a constant level. Some outliers can be found at around $5.9 \mathrm{~s}$ and $7.5 \mathrm{~s}$. At approximately eight seconds the five revolutions at full load are fulfilled and 


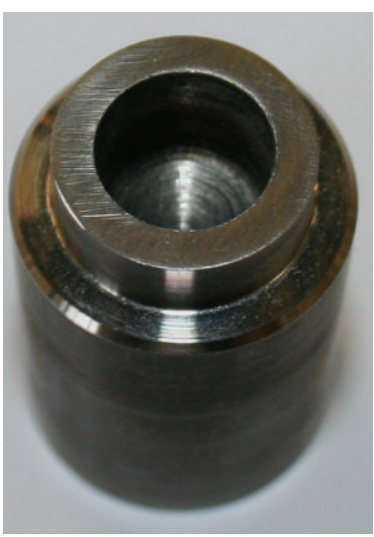

(a)

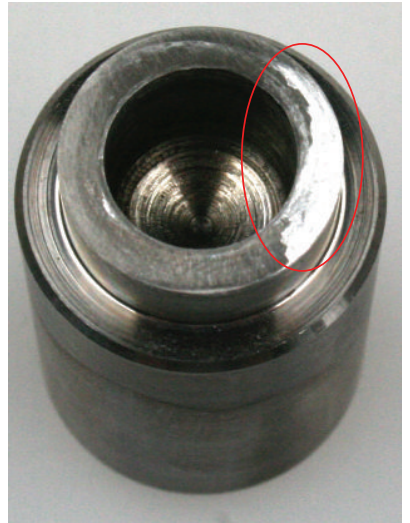

(b)
Figure 5: Tool specimen before (a) and after testing (b) with the compression-torsion-tribometer. Galling of aluminium on the tool specimen can be seen after testing (marked in red).

the pneumatic cylinder unloads. The rotation velocity curve is nearly constant at the designated 60 revolutions per minute. The experiment started with a rotating workpiece specimen; thus there is no starting ramp of the engine. Due to the quite constant rotation velocity also the slope of the curve of driven revolutions under pressure is constant. The shape of the revolution curve is discrete due to the used encoderwheel. The erratic behaviour of the rotation velocity is related to the necessary readjustment of the engine because of the inconstant torque during the experiment.

The transferred torque increases with nearly constant slope at the beginning of the experiment due to the increasing contact pressure. For a constant contact pressure the torque is constant for a short period (between $2.5 \mathrm{~s}$ and $3 \mathrm{~s}$ ) at approximately $27 \mathrm{Nm}$. Afterwards the torque increases again with a lower but again quite constant slope. In the time period between $6.5 \mathrm{~s}$ and $7.5 \mathrm{~s}$ a drop of the curve of about $5 \mathrm{Nm}$ takes place. At the end of the experiment and the separation of the two specimens, the transferred torque drops to zero. A still increasing torque after reaching a constant contact pressure is only possible if transformations at the contact area take place. This can be related to adhesion or abrasive effects.

An examination of the specimen surfaces after testing in the compression-torsion-tribometer helps in interpreting the measured curves. In Figures 5 and 6 the tool and workpiece specimens before and after testing in the compressiontorsion-tribometer are shown. It can be seen that the tool specimen has cold welded aluminium at approximately a quarter of the contact area. This could be a reason for the increasing torque curve in between the time period of $3 \mathrm{~s}$ and $6.5 \mathrm{~s}$ of the test. It can be assumed that the galling of the aluminium started at a small area and then increased with time.

Also the surface of the workpiece specimen at the contact area has changed after testing. The front layer of aluminium peeled away and a kind of aluminium-chip can be found on it. This might be a reason for the drop of the torque curve in Figure 3. On the inner lateral area of the encapsulation ring

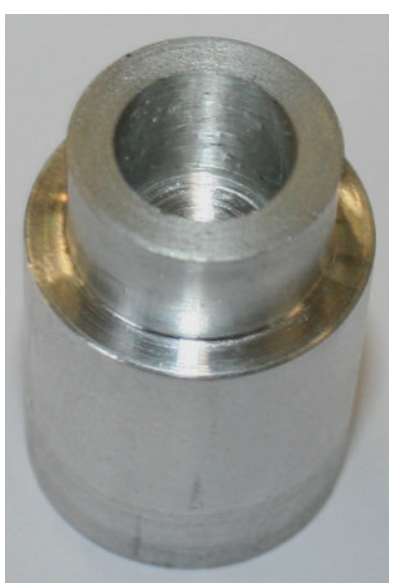

(a)

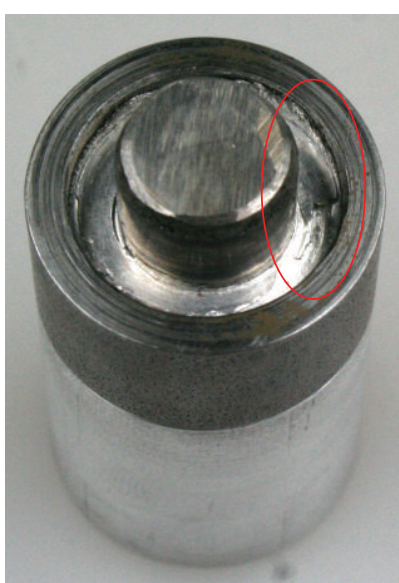

(b)
FIGURE 6: Workpiece specimen before (a) and after testing (b) with the compression-torsion-tribometer. Peeled away aluminium layers (marked in red) in the contact area can be found after testing.

and on the centering pin, plastically deformed aluminium can be seen. Due to the high contact pressure above the yield stress of the workpiece material, the aluminium flows into small interstices. In order to enable a rotational movement between tool and workpiece specimen a small gap between tool and encapsulation, respectively, centering pin is necessary. The aluminium yields during the test, closes that gap, and increases the contact area between both specimen parts. This will also have an influence on the measured torque curve and the interpretation of friction and wear at the surface and could be also a reason for the increasing torque curves described before.

3.2. Cyclic Loading. Also a cyclic loading of the specimens can be done with the compression-torsion-tribometer. These loading conditions should simulate a frequent use of the tool surface as it is usual in real cold extrusion processes. Moreover, higher loads (up to approximately $200 \mathrm{MPa}$ ) can be achieved with the compression-torsion-tribometer for the current used specimen design. In order to neglect the influence of a yielding of aluminium in the gaps between the specimens and to show just another possibility of the compression-torsion-tribometer, different cyclic loading states are presented for a much harder workpiece material than annealed pure aluminium. In the following two test configurations for the workpiece material the aluminium alloy AA6082-T6 is used. The tool material is again DIN 1.2343 (AISI H11) working steel and the setup is not lubricated.

In Figure 7 one can see the development of contact pressure and transferred torque for a rotation speed of $n=75$ revolutions per minute (rpm) and a load force of $F=18 \mathrm{kN}$. In this experiment the load directly dropped to zero after reaching the maximum contact pressure of approximately $190 \mathrm{MPa}$.

The generation of contact pressure requires about two seconds. The reduction of loading force takes approximately 


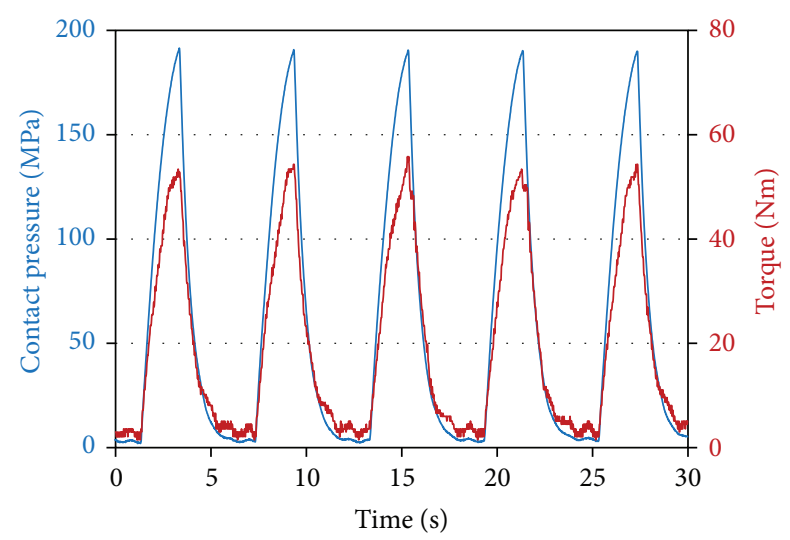

FIGURE 7: Cyclic loading with fast alternating contact pressure (blue) and resulting transferred torque (red) versus testing time.

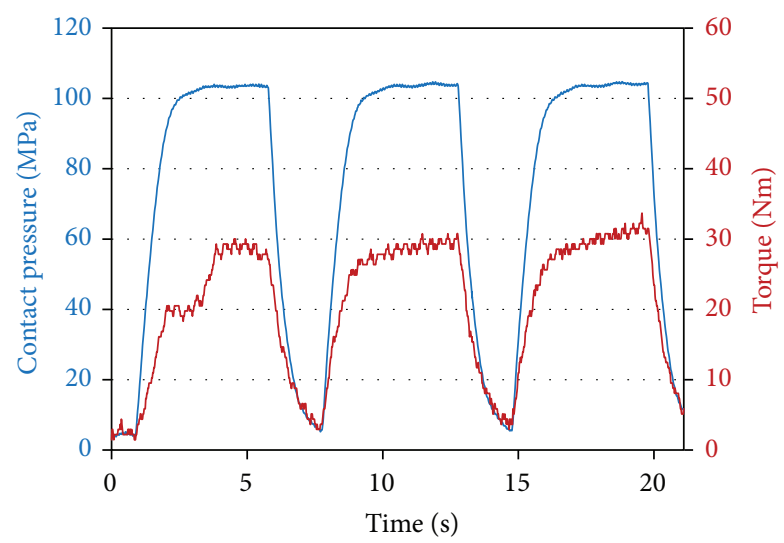

FIGURE 8: Cyclic loading with partially constant contact pressure (blue) and resulting transferred torque (red) versus testing time.

one second. With increasing contact pressure also the transferred torque increases. Simultaneous with the beginning of unloading the torque decreases. The maximal torque is $53 \mathrm{Nm}$. An interpretation of wear evolution can be done via a comparison of the peak levels of the torque curve. The general shapes of the different cycles are similar which means that no transformations of the contact area took place and the tool surface is still in initial state. That assumption is verified by a subsequent examination of the tool surface.

In Figure 8 again the development of contact pressure and transferred torque are plotted. In this case the load is reduced to $F=10 \mathrm{kN}$. Moreover only three loading cycles are examined. The rotation speed is again $n=$ $75 \mathrm{rpm}$. The contact pressure is increased to the chosen level and afterwards it is held constant for a defined time. The transferred torque increases again with rising contact pressure. The torque fluctuates even for constant contact pressure around a mean value. This behaviour is based on the different relative positions of the surfaces of both specimens due to the rotational movement.

An interpretation of the wear evolution can be done via a comparison of torque curve sections within the different loading cycles. In the first compression interval the torque reaches a plateau of about $20 \mathrm{Nm}$. At that time already the maximum contact pressure is reached. However, inside that first loading interval, the torque increases to a mean value of about $30 \mathrm{Nm}$. In the following two loading intervals the torque directly increases to $30 \mathrm{Nm}$ without going through the plateau before. It can thereby be stated that a galling of aluminium on the tool surface has already taken place in the first load cycle. A subsequent examination of the tool surface revealed cold welded aluminium on it.

The presented experiments show the possible measurements and results that can be obtained with the new compression-torsion-tribometer. The evolution of torque is a direct indicator for the wear process. Together with the measured glide length, velocity, and contact pressure, the complete load spectrum is well characterized. Altogether an examination of the complete tribological system is feasible. Further experiments are planned to reproduce the results and prove the assumptions.

\section{Conclusion and Future Work}

The new compression-torsion-tribometer presented in this work enables the indirect measurement of friction and wear for processes with contact pressure above the yield stress of the workpiece material. The measurement of the transferred torque is used as a direct indicator. Except for the thermal loading of the specimens, the complete tribological system can be examined. Additionally, a cyclic loading of the specimens in order to simulate a multiple use of the tool is feasible. Moreover, the experimental setup can be used for the examination of coatings and surface treatments on the tool and their tribological behaviour. Based on the planar contact surfaces, a subsequent examination of surfaces after the testing in the tribometer can be easily done via different microscopic techniques.

In future experiments the temperature development should be examined. Therefore, the integration of a thermocouple in the specimen parts is to be realized. Furthermore, an increase of the leak-tightness of the specimens should be accomplished and a partial deformation and related surface increase should be enabled. It might be assumed that a surface increase will also have an influence on the occurring adhesion effects. The feasibility of an evaluation of friction coefficients is to be verified. The influence of different surface treatments and layers can be examined in order to evaluate the wear resistance of the tool in a load spectrum similar to cold extrusion without lubrication. An extended investigation of the specimen surfaces before and after testing in order to achieve more information about the adhesion process is necessary. Finally, the contact pressure should be increased in order to reach high contact pressure to yield stress ratios for harder materials, for example, steel.

\section{Conflict of Interests}

The authors certify that no actual or potential conflict of interests in relation to this paper exists. 


\section{Acknowledgment}

The authors gratefully acknowledge the financial support of the Deutsche Forschungsgemeinschaft (DFG) within the priority Programme SPP 1676 "Dry Metal Forming."

\section{References}

[1] N. Bay, A. Azushima, P. Groche et al., "Environmentally benign tribo-systems for metal forming," CIRP AnnalsManufacturing Technology, vol. 59, pp. 760-780, 2010.

[2] G. Spur, H. Hoffmann, and R. Neugebauer, Eds., Handbuch Umformen: Handbuch der Fertigungstechnik, Hanser, München, Germany, 2012.

[3] J. A. Schey, Tribology in Metalworking: Friction, Lubrication and Wear, American Society for Metals, Ohio, Ohio, USA, 1983.

[4] M. Burgdorf, "Über die Ermittlung des Reibwertes für Verfahren der Massivumformung durch den Ringstauchversuch: Werkzeugmaschinen und Fertigungstechnik. Teil II: Umformtechnik," Industrie-Anzeiger, vol. 89, pp. 15-20, 1967.

[5] R. Kopp and F.-D. Philipp, "Physical parameters and boundary conditions for the numerical simulation of hot forming processes," Steel Research, vol. 63, no. 9, pp. 392-398, 1992.

[6] D. Hemyari, Methode zur Ermittlung von Konstitutivmodellen für Reibvorgänge in der Massivumformung bei erhöhten Temperaturen: Berichte aus Produktion und Umformtechnik (Band 43) [Dissertation], Darmstadt, Germany, 1999.

[7] R. Lauterbach, F. Lira, and E. G. Thomsen, "Friction under high normal pressures," Wear, vol. 10, no. 6, pp. 469-482, 1967.

[8] A. K. Pal, "A study of metallic friction phenomena with high normal pressure," Wear, vol. 26, no. 2, pp. 261-272, 1973.

[9] P. Hora, M. Gorji, and B. Berisha, "Modeling of friction phenomena in extrusion processes by using a new torsion-friction test," Key Engineering Materials, vol. 491, pp. 129-135, 2011.

[10] C. Becker, P. Hora, J. Maier, S. Müller, and S. Müller, "Experimental investigations of friction carried out with the TriboTorsion-Test and frictional modelling," Key Engineering Materials, vol. 585, pp. 25-32, 2014. 

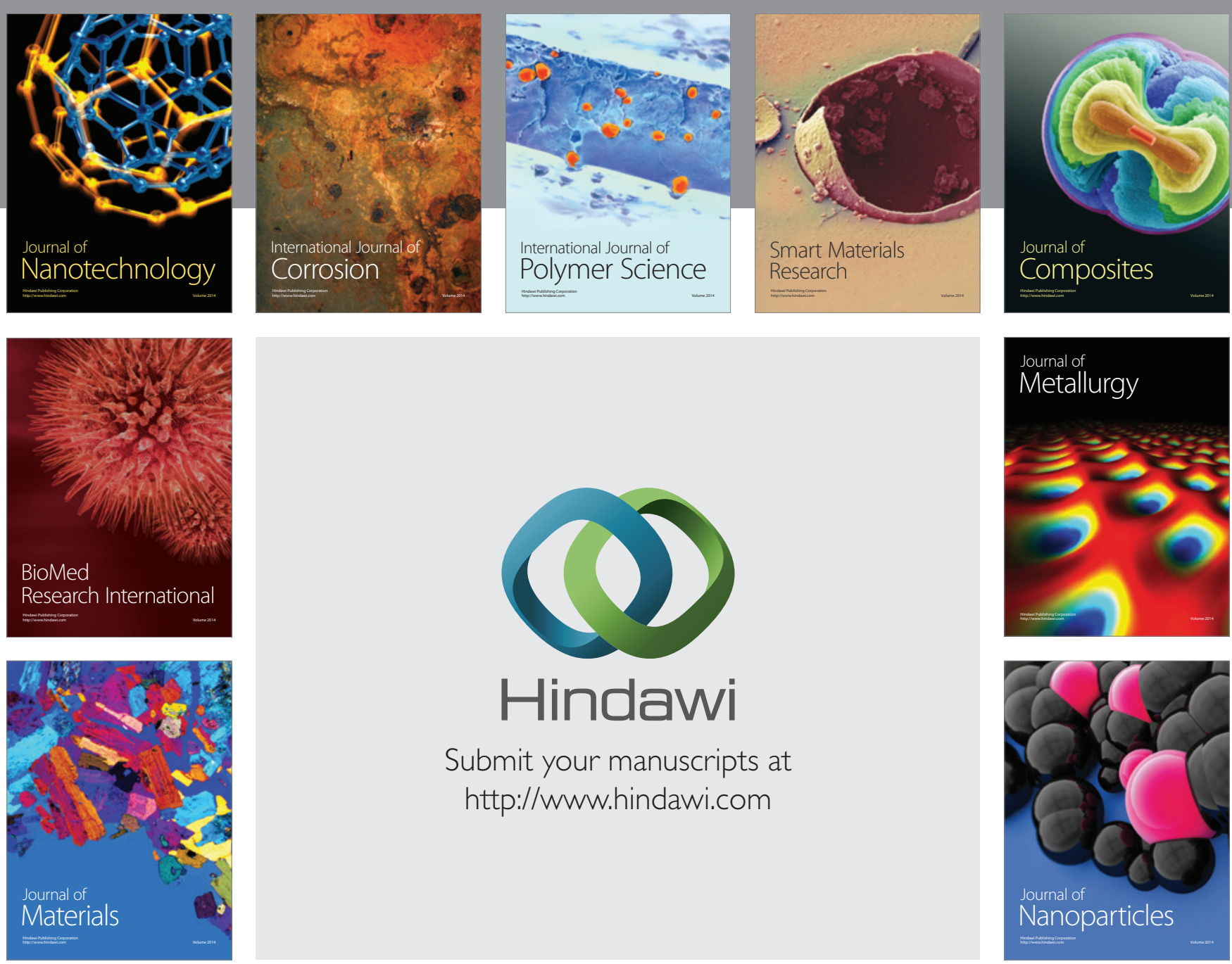

Submit your manuscripts at http://www.hindawi.com
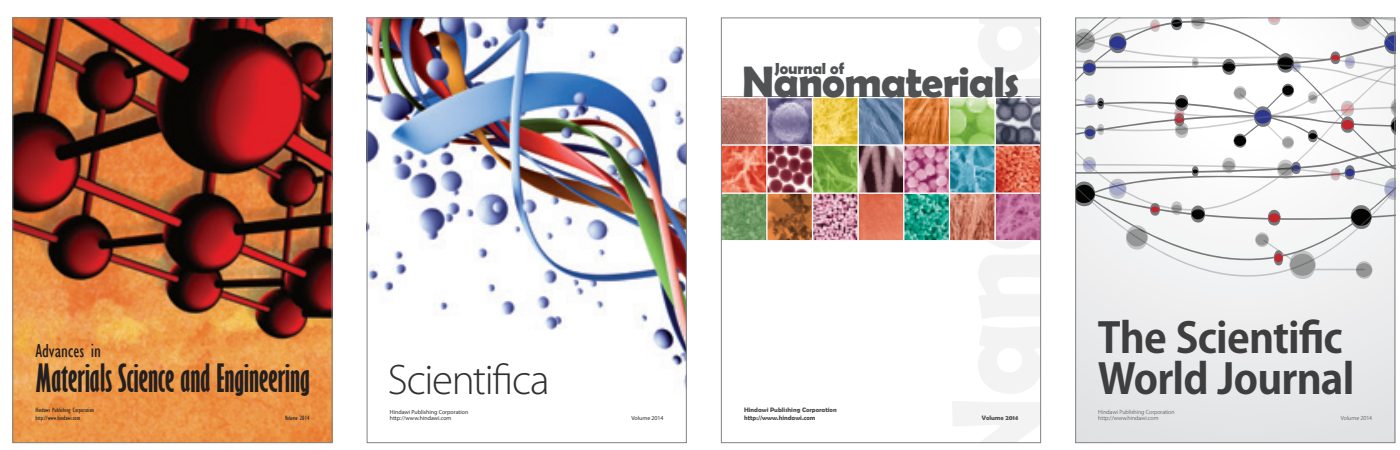

\section{The Scientific World Journal}
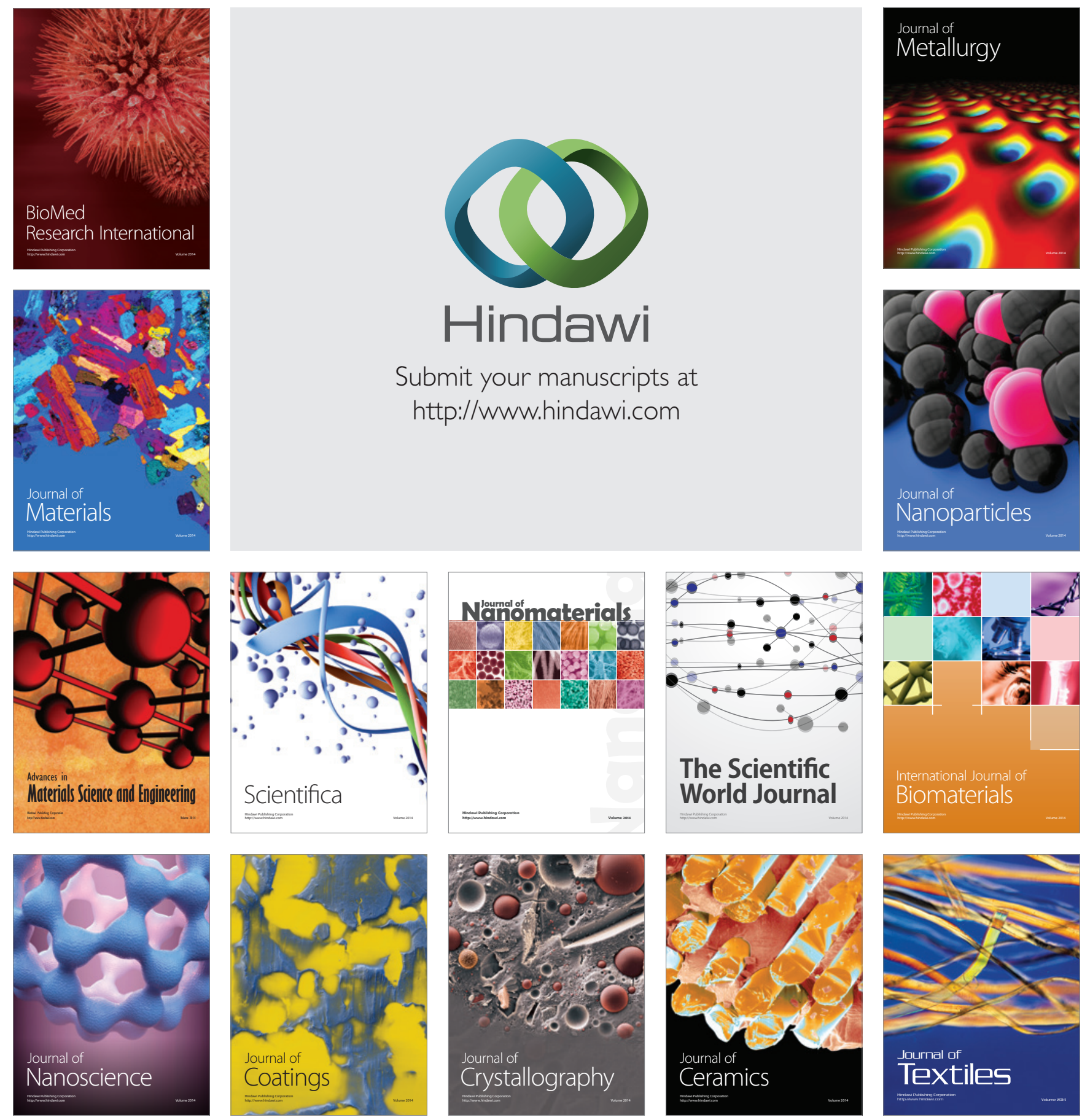